\title{
Sistema integrado de gestão e destinos ecoturísticos: possibilidade de aplicação do voucher digital no Parque Estadual do Jalapão
}

\section{Integrated management system and echotourist destinations: Possibility of application of digital Voucher in the State Park of Jalapão (Brazil)}

\author{
Dione Cley Bento de Abreu, Letícia Lima de Freitas
}

\section{RESUMO}

O ecoturismo é uma área do turismo de grande importância para conservação e preservação ambiental, e que é desenvolvido principalmente em Unidades de Conservação. Tais questões podem ser desenvolvidas a partir do controle de acesso de turistas e da arrecadação de taxas para ajudar a manter tais áreas protegidas. Todavia, muitas delas ainda não conseguem fazer uma gestão adequada destas Unidades de Conservação. Nesse sentido, a criação de um sistema integrado em gestão que possa coordenar e controlar as visitações nos atrativos, bem como o repasse de taxas, pode ser uma opção de instrumento de gestão, pois ainda são poucas as ferramentas que possibilitam a gestão de dados para subsidiar uma gestão integrada eficiente. Em tal contexto, o município de Bonito, no estado do Mato Grosso do Sul, se destaca no Brasil por criar um sistema de gestão integrada que auxilia na gestão dos atrativos turísticos do município, o Voucher Digital. O Parque Estadual do Jalapão (PEJ), tal qual o município de Bonito, é um destino ecoturístico brasileiro que se destaca por seus recuros naturais. Porém, há uma grande dificuldade de gestão dos atrativos do parque, devido a fatores como falta de recursos humanos, distância dos atrativos, controle de entrada de turistas, entre outros. Assim, o presente trabalho tem como objetivo verificar as implicações existentes na aplicação do Voucher digital como ferramenta de gestão integrada do ecoturismo no Parque Estadual do Jalapão. Dentro desse contexto, a metodologia aplicada neste estudo foi a de pesquisa qualitativa, com um nível exploratório e descritivo, e aplicação de entrevista com gestor do PEJ e diretor de turismo de Bonito-MS. Como resultados obtidos, temos que no PEJ o uso de um sistema integrado de gestão, nos moldes do Voucher digital, pode aperfeiçoar a qualidade do atendimento aos turistas, reduzir os impactos provocados pela atividade turística a partir do controle de capacidade de carga dos atrativos e proporcionar um ganho econômico maior para todos os envolvidos. Assim, para sua criação se faz necessário a criação de legislações específicas, um conselho de turismo, se fazer estudos de capacidade de carga nos atrativos, integrar a comunidade do entorno e melhorar as articulações institucionais.

PALAVRAS-CHAVE: Voucher Digital; Ecoturismo; Parque Estadual do Jalapão; Sistema Integrado de Gestão. 


\section{ABSTRACT}

Ecotourism is an area of tourism of great importance for environmental conservation and preservation, and which is mainly developed in Conservation Units. Such issues can be developed from the access control of tourists and the collection of fees to help maintain these protected areas. However, many of them still cannot properly manage these Conservation Units. In this sense, the creation of an integrated management system that can coordinate and control the visits in the attractions, as well as the transfer of fees, can be an option of management instrument, since there are still few tools that allow the management of data for efficient integrated management. In this context, the municipality of Bonito, in the state of Mato Grosso do Sul, stands out in Brazil for creating an integrated management system which assists in the management of the tourist attractions of the municipality, the Digital Voucher. The State Park of Jalapão (PEJ), like the municipality of Bonito, is a Brazilian ecotourism destination that stands out for its natural resources. However, there is a great difficulty in managing the attractions of the park, due to factors such as lack of human resources, distance of the attractions, tourists control, among others. Thus, the present work aims to verify the implications of applying the digital Voucher as an integrated ecotourism management tool in the Jalapão State Park. Within this context, the methodology applied in this study was of a qualitative research, with an exploratory and descriptive level, and application of interview with PEJ's manager and director of tourism of Bonito-MS. As obtained results, there is in the PEJ the use of an integrated management system, in the models of the digital Voucher, which can improve the quality of service provided to tourists, reduce the impacts caused by tourist activity through the capacity control of attractions and provide greater economic gain to everyone involved. Thus, for its creation, it is necessary to create specific legislations, a tourism council, carry out capacity studies on the loads of the attractions, integrate the nearby community and improve the institutional articulations.

KEYWORDS: Digital Voucher; Ecotourism.; State Park of Jalapão; Integrated system; Management.

\section{Introdução}

Tendo em vista a importância do ecoturismo na atualidade para a conservação do meio ambiente e para conscientização quanto à sustentabilidade, o tema proposto se enquadra na necessidade desenvolver um sistema integrado que possibilite o controle e ordenamento da atividade turística.

Nessa perspectiva temos como exemplo a cidade de Bonito (MS) como polo ecoturístico. É a principal cidade da região. Um destino conhecido nacional e internacionalmente por possuir atrativos naturais formados por águas transparentes, grutas, cachoeiras e cavernas.

Nessa perspectiva, tem-se como objeto de pesquisa a atividade ecoturística no Parque Estadual do Jalapão-PEJ, localizado no estado do Tocantins, uma prática que vem se desenvolvendo nessa região ainda de forma desordenada. Dessa forma surge a problemática de como a aplicação do Voucher digital como ferramenta de gestão integrada pode contribuir para o desenvolvimento ordenado do ecoturismo no Parque Estadual do Jalapão. 
Considerando a importância do ecoturismo na atualidade, como meio de conservação e proteção da biodiversidade, o tema proposto se justifica por ser necessária que as atividades realizadas em áreas naturais proporcionem a sociedade uma relação mais próxima com a natureza, promovendo benefícios socioeconômicos na localidade, onde as atividades ecoturísticas desenvolvidas possam ter um controle gerencial adequado, a partir de sistemas integrados de gestão no modelo de Voucher digital. Tal pesquisa irá contribuir na gestão do ecoturismo no PEJ, bem como no controle de acesso de turistas e no repasse das taxas adquiridas nos atrativos.

O presente trabalho tem como objetivo geral: Verificar as implicações existentes na aplicação do Voucher digital como ferramenta de gestão integrada do ecoturismo no Parque Estadual do Jalapão.

Como objetivos específicos deste trabalho, tem-se: - Descrever o modelo do Voucher digital de Bonito (MS); - Analisar a atual gestão do ecoturismo no Parque Estadual do Jalapão e; - Propor um modelo de Voucher digital como ferramenta de gestão integrada do ecoturismo no Parque Estadual do Jalapão, considerando-se que a prática desordenada dessa atividade pode gerar impactos negativos à natureza e as populações locais.

O segundo tópico foi desenvolvido a respeito do Sistema de Informação Gerencial e sua importância para a gestão do turismo, o ecoturismo e suas definições, e sobre o Voucher digital e o município de Bonito-MS.

Este trabalho teve como base teórica autores como Laudon e Laudon (2014), Batista (2012), Ruschmann (2005), Rezende e Abreu (2009); Lohmann e Panosso Netto (2008), CIA (2013), entre outros.

Em seguida, no terceiro tópico, tratamos sobre a metodologia utilizada neste artigo, que teve o caráter qualitativo, com níveis descritivo e explicativo e técnicas como pesquisa bibliográfica e documental, bem como do uso de entrevista.

No quarto tópico, tratamos sobre o PEJ e seus atrativos, da análise da gestão do ecoturismo, bem como da criação do Voucher digital, como ferramenta de gestão integrada.

\section{Sistema de informação gerencial}

Vivemos no período da informatização cobrando assim dos planejadores e gestores uma gestão estratégica competente, que pode ser aprimorada com recursos disponibilizados pelos sistemas de informação que oferecem recursos tecnológicos e computacionais para garantir mudanças significativas na gestão.

Segundo Laudon e Laudon (2014), sistemas de informação gerencial são vários elementos inter-relacionados que coletam, processam, e distribuem informações para amparar organizações a tomar decisões, 
controlar e coordenar as mesmas. O sistema de informação gerencial irá possibilitar aos gerentes e trabalhadores a avaliar dificuldades e inventar novos produtos.

Rezende e Abreu (2009) defendem a ideia de autores como Oliveira (1988) e Stair (1998) de que os sistemas de informação gerencial podem contribuir como um todo e no sucesso da organização. Esses impulsos podem favorecer a empresa, os clientes e usuários que interagem com os sistemas de informação gerencial. Portanto, as empresas buscam alcançar por meio dos sistemas de informação gerencial os benefícios que darão apoio às tomadas de decisão, buscando agregar valor aos produtos, obter menos erros nas informações e o aperfeiçoamento nos sistemas.

Vários fatores podem ser ressaltados para a solução de problemas, e esses elementos acrescentarão uma capacidade de tomar decisões assertivas, proporcionando assim soluções e a satisfação dos clientes e empresa. Contudo, o processo de informação nas empresas não se restringe apenas a um sistema de informática perfeito, mas também necessita de um bom profissional que alimente esse sistema.

Em relação ao turismo, os sistemas de informação gerencial trazem ao turista a disponibilidade de atender e realizar suas necessidades e desejos. Ao comprar um produto turístico, o cliente espera uma satisfação ou mesmo a realização de sonhos, pois o turismo é um produto intangível, que não pode ser tocado nem testado antes. A tecnologia passou a ser ferramenta essencial para que as empresas do setor turístico atuem com qualidade e se tornem competitivas no mercado, para que os turistas tenham suas necessidades e anseios atendidos e os profissionais da área possam planejar com apoio em informações confiáveis.

Conforme Batista (2012) os sistemas integrados geram o movimento de informação entre os setores da empresa, como as atividades básicas de uma organização, financeiro e recursos humanos. Com objetivo de centralizar em um banco de dados todas as informações internas e externas unificando assim os dados em uma plataforma. Dessa forma, estabiliza as operações da empresa em um espaço computacional, tornando maior a integração de elementos para que as empresas alcancem a eficiência.

Ainda segundo o autor, os sistemas integrados têm como foco as ligações entre os clientes e fornecedores para o aumento da sua eficiência, tendo em vista a relação da empresa com seus colaboradores.

Nesse sentido, os sistemas integrados também trazem muitas vantagens para a gestão do turismo e tem garantido sucesso nas áreas onde estão ocorrendo à prática do ecoturismo, por exemplo, tanto na forma de controle de visitantes que garantem a conservação do ambiente como na geração de receita para o município e na melhoria do serviço para os turistas. Conforme Ruschmann (2005) a delimitação da capacidade de carga dos atrativos turísticos limita o acesso de turistas e coordena a atividade turística nas regiões onde o turismo de massa pode causar danos irreparáveis a natureza. Com o controle de capacidade de carga os preços aumentam com o aumento da demanda, porém os recursos são investidos em benefícios para o turista, comunidade receptora e para o meio ambiente. 
Tais sistemas integrados,

\begin{abstract}
Apresentam um conjunto de módulos de software integrados e um banco de dados central; este permite que os dados sejam compartilhados pelos diferentes processos de negócios e áreas funcionais de toda a empresa (LAUDON e LAUDON, 2014. p 296).
\end{abstract}

Esses sistemas integrados disponibilizam informações importantes que resultam na facilidade em tomar decisões. Os gestores de destinos turísticos podem ter acesso aos dados fornecidos pelos sistemas integrados, no que diz respeito à demanda e oferta, por exemplo. Usam tais informações para decidir o que deve ser produzido e o que será vendido posteriormente, conforme explica Laudon e Laudon (2014).

Verificou-se que os sistemas integrados para os destinos turísticos têm alavancado a atividade turística, aumentando a eficiência nas empresas que oferecem serviços turísticos e garantindo a prestação de um serviço com maior qualidade e rapidez nas informações.

\title{
Ecoturismo
}

O querer estar próximo à natureza é uma das motivações que levam os turistas aos locais com recursos naturais para fugirem da monotonia do dia a dia nos centros urbanos, com isso a conformidade do turismo com o meio ambiente é um fator indiscutível, já que um fundamenta o outro.

O relacionamento do turismo com o meio ambiente tem se caracterizado por alguns aspetos peculiares e que deverão ser considerados nas ações e estratégias do planejamento da atividade. Para que o desenvolvimento do turismo ocorra de forma equilibrada é necessário estabelecer critérios para a utilização dos espaços. De acordo com suas características, a fragilidade dos ecossistemas naturais e a originalidade cultural das populações receptoras. (RUSCHMANN, 2005, p 127).

O turismo depende da qualidade e da proteção do meio ambiente, pois é este sua principal matéria prima. A sustentabilidade deve estar incluída não só ao meio ambiente natural, mas também ao urbano onde acontecem interações sociais em maior densidade, e onde surge grande parte da degradação ambiental, como poluição dos rios, assoreamento, acúmulo de lixo, poluição do ar, entre outros.

Nessa perspectiva, vê-se que a prática do turismo tem relação estreita com a paisagem e o ambiente natural, levando-se em consideração que o homem costuma expressar em sua maioria o desejo pelo conhecimento de outros lugares diferentes do seu habitual, como as paisagens naturais. 
Somando a este fato a definição de paisagem definida a partir do olhar do observador e carregada de componentes histórico-culturais (LOHMANN; PANOSSO NETTO, 2008).

De tal modo, surge à prática do ecoturismo, que provoca principalmente responsabilidade, tanto ambiental quanto social, isso porque envolve além da natureza as comunidades locais e a sua maneira de viver. Porém, a característica individualista e o desejo de acumulação de bens da sociedade moderna são limitações à urgente necessidade de práticas econômicas sustentáveis e sóbrias, pensadas antes de serem postas em prática e medidas segundo sua relevância.

O ecoturismo é um ramo do turismo que mais cresce atualmente, proporciona a sociedade uma aproximação com os ambientes naturais e possibilita uma relação mais próxima com a natureza desenvolvendo benefícios socioeconômicos na localidade.

Ecoturismo é despertar a vontade de aproximar-se da natureza e conseguir estar em contato com o que ela tem de mais belo a oferecer, é cultivar a potencialidade local tendo em vista à conservação e o desenvolvimento, protegendo a biodiversidade e a cultura, garantindo o menor impacto negativo possível. Alguns elementos necessitam ser observados para que o ecoturismo seja uma ação que gere resultados benéficos para todos aqueles envolvidos: clientes, gestores, comunidade local e fornecedores (CÉBALLOS LASCURÁIN, 2005).

Para Cia (2003), o ecoturismo é um ramo do turismo que usa de maneira sustentável os bens naturais e culturais, busca realizar visitas em ambientes naturais inserindo as comunidades locais nessa atividade e ao mesmo tempo exercendo a conservação da natureza através da interpretação do ambiente. Após várias devastações nas matas e florestas ainda existem pequenas reservas em propriedades privadas ou parques que são usadas para uso consciente. Dessa forma o ecoturismo veio para garantir a conservação socioambiental.

De acordo com Rodrigues (2003), o ecoturismo é uma prática que gera renda e causa pouco impacto na natureza, que se destinam as áreas naturais e culturais, e por meio dessa atividade educativa possibilita a conservação do local visitado e sua biodiversidade, gerando benefícios para as populações locais.

Para que a receita gerada do ecoturismo se reverta em benefícios para o desenvolvimento econômico e a conservação, faz-se necessário a utilização de alguns fatores essenciais:

- Estipular taxas turísticas;

- Utilizar o dinheiro arrecadado por meio dessas taxas para financiar o desenvolvimento do ecoturismo e de estratégias tradicionais de conservação;

- Aumentar a contribuição do ecoturismo para o desenvolvimento econômico de comunidades próximas às áreas onde se desenvolvem atividades ecoturísticas. (LINDBERG, 2005, p.144). 
As atividades realizadas nesse segmento são: trilhas, contato com a comunidade local, percursos de bicicletas, mergulho livre, entre outras. Com isso os visitantes são sensibilizados quanto à importância de respeitar a natureza e garantir o menor consumo possível de recursos não renováveis.

O crescimento do interesse turístico do homem pela natureza foi influenciado pelo fenômeno ambientalista que ocorreu ao final dos anos 1960. Foi a partir daí que a busca por destinos culturais e naturais autênticos e tradicionais das regiões visitadas tornaram-se precursores do que hoje é denominado Ecoturismo (SOLDATELI, 2005).

Como esta modalidade traz resultados positivos para as unidades de conservação e cidades circunvizinhas, o parque estadual é uma das classificações que admitem a realização de visitas para diversão e pratica do ecoturismo. De tal forma é necessário o incentivo do ecoturismo nas áreas protegidas para que possa garantir a conservação das mesmas, devendo haver um planejamento nessas áreas que ofereça a sociedade ambiente que disponibilize contato com a natureza e que sensibilize os visitantes quanto à importância da conservação dos recursos naturais (JESUS; SELVA, 2009).

Os turistas que frequentam as áreas naturais e tem contato direto com a fauna pode causar perturbações na alimentação e na reprodução das espécies. Soma-se a isto a poluição do ar causado pelos meios de transportes e a modificação feita pelo homem nas paisagens, modificando e transformando em estruturas artificiais, como edifícios, pontes. Contudo as implantações planejadas dessas estruturas artificiais no meio ambiente podem minimizar os impactos negativos conservando assim as características naturais e culturais da localidade. (SOLDATELI, 2005).

\section{Voucher Digital e Bonito (MS)}

A cidade de Bonito está localizada no estado do Mato Grosso do Sul, na região da serra da Bodoquena no Centro-Oeste brasileiro. É a principal cidade da região, conhecida como pólo do ecoturismo. Bonito é um destino conhecido por possuir diversos atrativos naturais formados por diversos rios, grutas, cachoeiras e cavernas.

O surgimento do ecoturismo em Bonito teve início em 1988, com poucas visitas em alguns atrativos como a llha do Padre, a Gruta do Lago Azul e ao Balneário Municipal. Após essas visitações o destino passou a ser motivo de reportagem por emissoras de televisão de grande importância no Brasil, sendo conhecido nacional e internacionalmente, o que ocasionou no crescimento da demanda em busca destes atrativos (CIA, 2003).

Porém, nesse período ainda não haviam condições adequadas para atendimento aos turistas. Somente em 1993 iniciou-se a primeira etapa para estruturar a forma de organizar o turismo no município. Assim, o Instituto Brasileiro de Turismo (EMBRATUR), juntamente com outros órgãos ofereceu o curso de guia de turismo regional com especialização em atrativos naturais. 
Como aponta Vieira (2003), com o intuito de controlar a exploração dos recursos naturais foi adotada uma política de sustentabilidade determinando o acompanhamento dos turistas por guias locais credenciados pela prefeitura e registrados na EMBRATUR, a partir da Lei municipal n. ${ }^{\circ} 689 / 95$ que tornou os guias de turismo um fator indispensável e obrigatório nos passeios turísticos locais. A capacidade de carga nos atrativos também passou a ser controlada para que não houvesse um comprometimento da riqueza ecológica de Bonito.

Para Oliveira e Sabino (2013) a imensa busca por esse destino trouxe a necessidade de se criar medidas para coordenar a visitação e garantir o menor impacto no ambiente. Começaram a surgir os meios de hospedagem, e com eles a lei municipal regulamentando a atividade, e o mais importante passo, a criação do Conselho Municipal de Turismo (COMTUR), conforme explica Cia (2003).

A Lei municipal n. ${ }^{\circ 695 / 95}$ estabelece o COMTUR, e a resolução

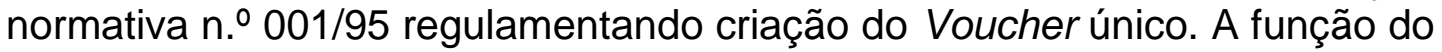
COMTUR é a de ordenar à atividade turística, divulgando os acontecimentos turísticos em Bonito, garantindo à profissionalização da mão de obra local, dando suporte à comunidade envolvida.

Tal órgão é responsável pela organização da gestão inserida no município regularizando a atividade, fiscalizando a execução das regras de utilização dos recursos naturais até o modelo padronizado de atendimento ao turista. O COMTUR é formado por um representante de cada setor da cadeia produtiva do turismo e por outros do poder executivo municipal, sendo o presidente um representante do segmento turístico. O Quadro 1 mostra a formação do COMTUR formado pelos representantes de cada setor.

Quadro 1: Formação do Conselho Municipal de Turismo- COMTUR Bonito (MS).

Frame 1: Formation of the Municipal Tourism Council.

\begin{tabular}{l|l}
\hline Nome da Entidade/ Instituição & SIGLA \\
\hline $\begin{array}{l}\text { Associação Bonitense dos Proprietários de Agências de } \\
\text { Ecoturismo }\end{array}$ & ABAETUR \\
\hline Associação Bonitense de Hotelaria & ABH \\
\hline Associação Comercial e Empresarial de Bonito & ACEB \\
\hline $\begin{array}{l}\text { Associação dos Proprietários de Atrativos Turísticos de Bonito } \\
\text { e Região }\end{array}$ & ATRATUR \\
\hline Associação Brasileira de Bares e Restaurantes de Bonito/MS & ABRASEL \\
\hline Sindicato dos Guias de Turismo de Mato Grosso do Sul & SINDTURMS \\
\hline Bonito Convention \& Visitors Bureau & BCVB \\
\hline Instituto Chico Mendes de Conservação da Biodiversidade & ICMBio \\
\hline Instituto do Patrimônio Histórico e Artístico Nacional & IPHAN-MS \\
\hline Sindicato Rural e Patronal de Bonito & \multicolumn{1}{c}{---} \\
\hline Universidade Federal de Mato Grosso do Sul & UFMS \\
\hline Poder Público & IASB \\
\hline Instituto das Águas da Serra da Bodoquena &
\end{tabular}

Fonte: *O Autor, Baseado em Bonito (2011). Source: Author.

O Voucher único é um instrumento de gestão turística que foi inserido em Bonito em 1995 com o intuito de controlar a atividade turística e diminuir os impactos causados no meio ambiente. A prefeitura passou a controlar o 
número de visitantes e a cobrar impostos sobre os serviços dos envolvidos da cadeia produtiva do turismo. Esta estruturação permitiu rendimentos inumeráveis a população local e para o meio ambiente que dava um grande passo para a sustentabilidade, uma questão ainda pouco discutida.

Para que os sítios, fazendas e atrações recebam licença para iniciar uma operação turística no município de Bonito, é obrigatoriamente necessário que se desenvolva um estudo de impacto ambiental e um plano de manejo no local que será desenvolvida a atividade, visando manter a integridade geológica, biológica, histórica e cultural. Considerando que Bonito possui na sua grande maioria as atribuições mencionadas acima 0 município aderiu um sistema onde foi estabelecido regras na implantação e operação (Dados da entrevista 01, 2016).

Com o avanço da tecnologia surgiram necessidades de se implantar um sistema mais sofisticado que garantisse o melhor funcionamento para os turistas e para os profissionais do setor turístico. Assim criou-se o Voucher digital (Figura 1) por meio do Decreto $\mathrm{n}^{\circ}$ 062, de 04/05/2010, com embasamento no artigo 100 da Lei Complementar $n^{\circ} 037$ de 12/12/2000.

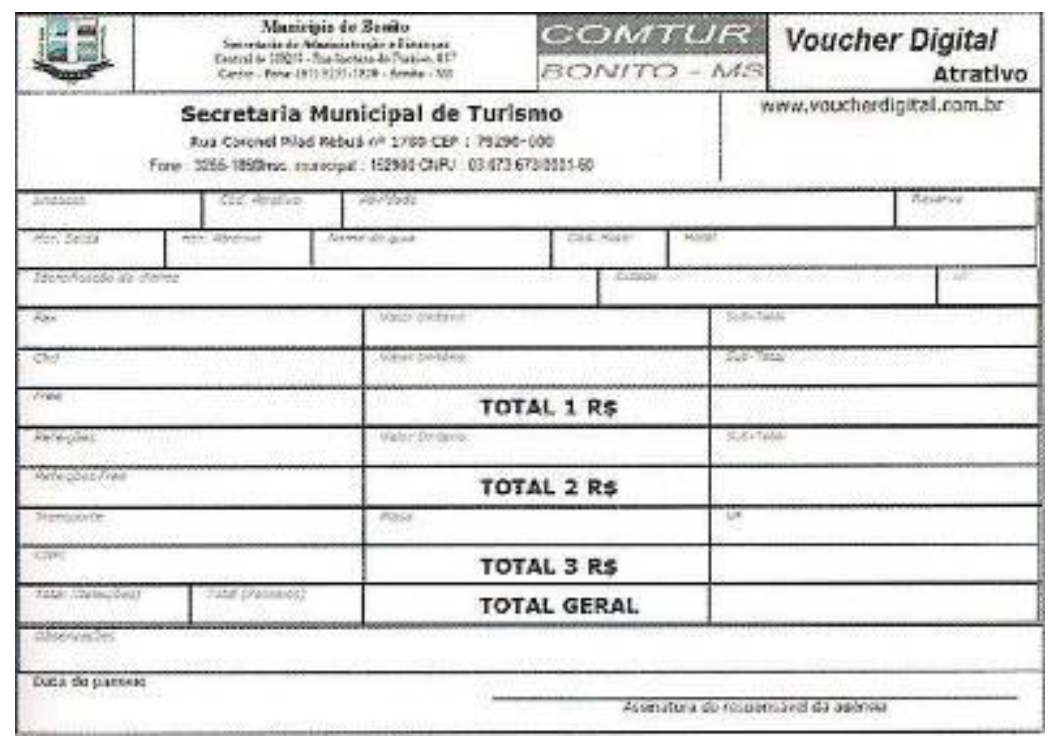

Figura 1: Modelo do Voucher digital.

Figure 1: Digital Voucher Model.

Fonte: Leite (2015).

Source: Leite (2015).

Esse sistema permite registrar as intervenções realizadas pelas operadoras de turismo e agências para o recolhimento do Imposto Sobre Serviço de Qualquer Natureza (ISSQN) (LEITE, 2015).

O planejamento para a execução desse projeto foi pensado para que impactasse de maneira positiva o atendimento dos turistas. Dessa forma, foram realizadas reuniões com os participantes do trade turístico para esclarecimento das medidas tomadas. 
A criação do Voucher digital foi um grande passo para o crescimento, controle e organização turística em Bonito, passando a ser modelo de gestão adotado por outras localidades que buscam um ordenamento da atividade turística que garanta a conservação ambiental e proporcione uma distribuição igualitária dos recursos gerados com o turismo para cada setor envolvido (CIA 2003).

Para que possam ter acesso ao Voucher digital às agências e operadoras de turismo solicitam registro de contribuintes do município de Bonito. Com isso, são realizados procedimentos de análises de documentos da empresa e após isso é efetivado a capacitação operacional e liberada a senha de acesso pela Secretaria Municipal de Administração e Finanças (LEITE, 2015).

De acordo com o entrevistado 1 , os atrativos ao formatarem 0 planejamento e tarifário para apresentar ao público e parceiros o valor de seu produto, já se cria uma tabela onde consta o percentual que ficará para cada setor envolvido como guias, agências, transporte prefeitura e outros, o valor do percentual a ser repassado fica acordado em reuniões do COMTUR que estão presentes o poder público e os representantes de cada setor do turismo.

As fiscalizações nos atrativos são de responsabilidade dos órgãos competentes, Polícia Militar Ambiental quando competir a áreas naturais, Instituto do Patrimônio Histórico e Artístico Nacional (IPHAN) que garante a preservação do patrimônio cultural, o Ministério Público quando houver o registro de excesso no limite de visitação nos atrativos, pois o mesmo acompanha em tempo real toda a movimentação de reserva dos atrativos credenciados. Todavia qualquer membro da sociedade também pode oferecer a denuncia ao Ministério Público (Dados da entrevista 01, 2016).

O Voucher digital garante a prestação de um serviço direto ao turista, no qual a venda é intermediada por agências e operadoras, pressupondo que cada membro integrante da rede de prestação de serviços, cumprirá seu compromisso, seguindo regras pré-estabelecidas, respeitando e preservando a natureza e colaborando para um turismo consciente e planejado.

Assim, segundo Vieira (2003), pode-se ver que com o desenvolvimento da atividade turística em Bonito, a comunidade local estabeleceu formas de se relacionar com o meio ambiente e com os visitantes, passando a ser a maior beneficiada com geração de empregos, renda e receita para o município. Esse modelo de gestão instituído em Bonito passou por um processo de organização social, discutido e inserido em comum acordo com gestores locais, expressando a busca e o desejo de organização da atividade turística.

\section{Aspectos metodológicos}

O presente artigo teve como objeto de estudo o Parque Estadual do Jalapão, analisando quais as implicações existentes na aplicação do Voucher digital como ferramenta de gestão integrada do ecoturismo. 
Tal pesquisa teve como metodologia o caráter qualitativo, com níveis descritivo e explicativo e técnicas como pesquisa bibliográfica e documental, bem como do uso de entrevista. A análise dos resultados se deu a partir da técnica de análise de conteúdo. de

O uso da metodologia de caráter qualitativo se justificativa pelo fato

A pesquisa qualitativa preocupa-se com um nível da realidade que não pode ser quantificado, trabalha com o universo de significações, motivos, aspirações, crenças, valores e atitudes, o que corresponde a um espaço mais profundo das relações, dos processos e dos fenômenos que não podem ser reduzidos à operacionalização de variáveis. Tem um tipo de objetividade e de validade conceitual que contribui ao pensamento científico (MOESCH, 2002, p. 62).

Utilizou-se o nível descritivo, que para Oliveira (2008, p. 39) é "recomendável desde a definição do objeto de estudo, passando pela delimitação do lugar, tempo de revisão de literatura e coleta de dados". Após utilizou-se o nível explicativo que "procura identificar os fatores que determinam ou contribuem para a ocorrência dos fenômenos" (DENCKER, 2007, p. 125).

No decorrer da pesquisa foram utilizadas técnicas para a realização da coleta de dados e informações, como pesquisa bibliográfica e documental, sobre os estudos científicos referentes ao tema, com materiais como livros, artigos, leis e relatórios. Foram utilizados autores como Batista (2012), Céballos Lascuráin (2005) e Leite (2015).

Outra ferramenta metodológica usada para explorar os objetivos propostos foi às entrevistas realizadas com a gestora do PEJ e com o diretor de turismo da cidade de Bonito-MS, por meio de e-mails trocados no qual foram feitas doze (12) perguntas para a gestora do PEJ e cinco (5) para o diretor de turismo de Bonito, que se encontra em apêndice no decorrer do presente trabalho.

A partir dos dados levantados, foi feita a análise do conteúdo das entrevistas, comparando a base teórica apresentada, a fim de responder às questões propostas neste trabalho.

\section{Análise e discussão dos resultados}

\section{Parque Estadual do Jalapão}

Situado no extremo leste do estado do Tocantins (Figura 2), o PEJ foi instituído pela Lei Estadual $n^{\circ} 1.203$ de 12 de janeiro de 2001, e possui uma extensão territorial de 158.885 hectares, sendo o maior parque do estado do Tocantins. A área que se localiza o PEJ abrange os municípios de Mateiros, Ponte Alta, São Felix do Tocantins e Novo Acordo. 


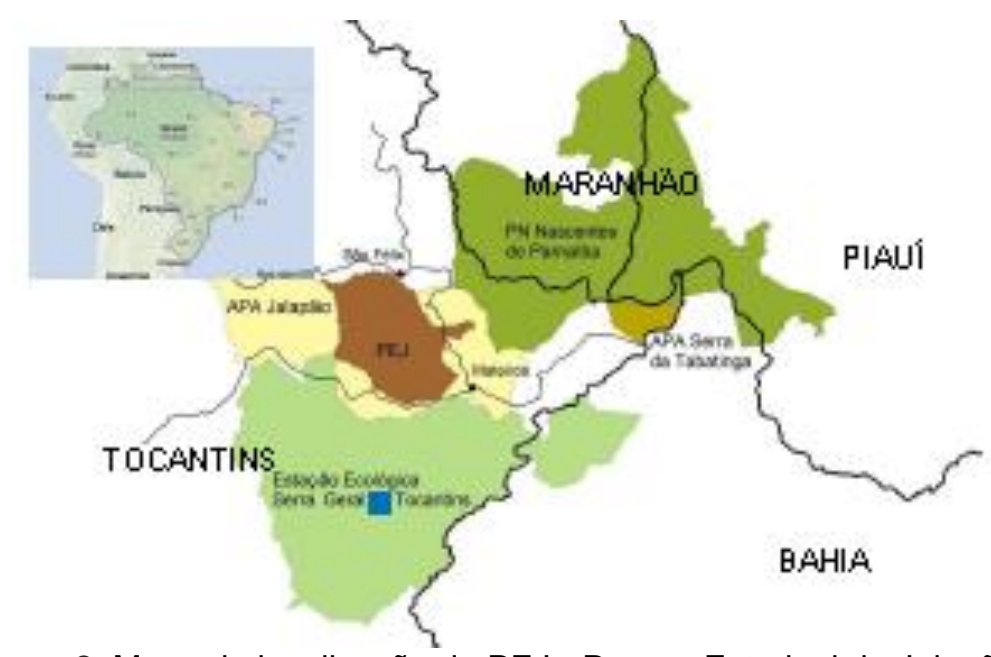

Figura 2: Mapa de localização do PEJ - Parque Estadual do Jalapão (TO).

Figure 2: Location map PEJ - Jalapão State Park (TO-Brazil).

Fonte: Santos; Pequeno; Ribeiro; Freitas (2016).

Source: Santos; Pequeno; Ribeiro; Freitas (2016).

O PEJ tem por objetivo a conservação e preservação dos recursos naturais de sua localidade, dessa maneira é permitida apenas aproveitar-se indiretamente do que é oferecido por ele, fato que restringe a exploração inadequada.

O turista que pretende viajar para o PEJ por via terrestre pode escolher duas maneiras, a partir da capital do estado, Palmas, através das rodovias TO - 020, percurso que liga Palmas à Novo Acordo com $115 \mathrm{~km}$, TO-110 de Novo Acordo à São Felix do Tocantins com $147 \mathrm{~km}$ de percurso, em seguida pela TO-110 entre São Felix do Tocantins e Mateiros, $79 \mathrm{~km}$. Outro percurso que dá acesso ao PEJ é a TO-050 que chega a Porto Nacional $(60 \mathrm{~km})$, uma rodovia pavimentada em seguida é a TO-255, que passa por Ponte Alta do Tocantins $(135 \mathrm{~km})$ até chegar à Mateiros (165 km de estrada de terra) (THE NATURE CONSERVANCY, 2012).

A criação do PEJ contribuiu para o aumento do ecoturismo no Tocantins que colaborou para a diminuição dos impactos ambientais causados pela expansão da agropecuária no Estado, como por exemplo, as derrubadas da vegetação nativa para a plantação de pastos e 0 assoreamento de rios provocando degradação no solo. Além disso, as queimadas no período de estiagem provocam danos às comunidades e destrói a fauna e flora (CHAGAS, 2007).

Os fatores que atraem as pessoas a conhecer o PEJ são suas inúmeras cachoeiras, os canyons, o fervedouro, as dunas, seu clima quente, entre outros atrativos que fizeram do PEJ um grande potencial turístico.

Segundo Nascimento et al. (2013) a presença dos turistas no PEJ está associada ao desejo de conhecer as paisagens do cerrado, as veredas com o capim dourado e vários animais que estão em risco de extinção. Diante disso o ecoturismo cresce cada dia mais atraindo pessoas para os atrativos locais que inclui também as comunidades vizinhas. 
Um dos atrativos bastante procurado pelos visitantes é a cachoeira da formiga que fica localizada a aproximadamente $31,5 \mathrm{~km}$ do município de Mateiros, formada por uma pequena queda d'água, rodeada por árvores altas, samambaias e palmeiras nativas. Uma piscina de águas cristalinas embaixo da cachoeira atrai o turista para um mergulho onde se podem observar as areias calcarias no fundo das águas. Esse atrativo encontra-se em propriedade particular e pode ser visitado durante todo o ano. O controle de visitação é realizado através de ingresso vendido individualmente, porém o grande fluxo de visitantes tem comprometido o solo e a vegetação local (MARINHO et al., s/d).

Outro atrativo bastante conhecido são as dunas de areia dourada. É uma paisagem inesquecível ao olhar dos turistas, as mesmas estão em constante movimento provocado pelos ventos, chegando a medir 30 metros de altura.

Também podemos destacar o fervedouro em meio à vegetação fechada, é um lugar bastante visitado por possuir uma m rodeada de riachos e brejos, a água é a responsável pela forte pressão que provoca o chamado fenômeno da ressurgência e isso impossibilita que alguém se afunde nele.

O PEJ possui também outros fervedouros que são bastante visitados por turistas, a comunidade Mumbuca que produz artesanato e recebe as pessoas que buscam conhecer a cultura local. Outro atrativo bastante visitado por turistas no PEJ é a Serra do Espírito Santo, que oferece uma vista deslumbrante para aqueles que vencem o desafio de subir a serra por uma trilha para apreciar o nascer do sol e para os que preferem o pôr do sol.

\section{Gestão do Ecoturismo no Parque Estadual do Jalapão}

Nas Unidades de Conservação (UC) tem-se desenvolvido o ecoturismo como uma maneira de aproximação a natureza e a realização da educação ambiental, onde o ecoturismo também é uma alternativa econômica para o crescimento da região situada na UC. As práticas do turismo nessas localidades têm causado grandes mudanças ambientais e socioculturais por não possuir uma gestão adequada.

Tal análise sobre a gestão do ecoturismo no PEJ foi construída a partir de entrevista com doze (12) perguntas, realizada com atual supervisora e também a partir de artigos, relatórios e documentos referentes ao objeto de estudo.

O PEJ, como citado anteriormente é uma área protegida que mantém a permanência da fauna e flora que vive em constante ameaça em outros ambientes. Somando a riqueza exuberante da biodiversidade estão os rios, cachoeiras, lagoas e ressurgências hídricas que fazem do Parque um patrimônio primordial para a qualidade de vida, conforme explica The Nature Conservancy (2012).

Ao analisar a atual gestão do PEJ identificou-se que assim como as outras UC do Tocantins o PEJ é de responsabilidade do Instituto Natureza 
do Tocantins (NATURATINS). A supervisão do Parque está subordinada a uma diretoria de biodiversidade e áreas protegidas.

Em relação aos recursos humanos, o PEJ conta com uma supervisora, três (3) técnicos, dois (2) guarda-parque efetivos, três (3) Assistentes de Serviços Gerais; cinco (5) brigadistas, todos contratados anualmente e uma brigada temporária com dez (10) pessoas para apoiar a unidade no período de seca (maio a outubro). É função da supervisora coordenar os trabalhos realizados na unidade, mas existe uma hierarquia institucional onde as decisões são levadas em consideração. Além disso, o PEJ possui um Conselho Consultivo atuante que auxilia na gestão da UC. (Dados da entrevista 02, 2016).

O Conselho é Consultivo e não deliberativo, porém possui um regimento interno, além de ser um conselho atuante e que se reúne periodicamente para tratar de todos os assuntos relacionados à unidade.

Atualmente o PEJ trabalha com cinco programas relacionados aos objetivos básicos de preservação da área em questão, são eles: Operacionalização; Proteção e manejo; Integração com o interior e entorno; Uso público; e Pesquisa e monitoramento. Com exceção deste último programa, todos tem um inspetor de recursos naturais responsáveis pelas ações (Dados da entrevista 02, 2016).

Existe um sistema de gestão de unidades de conservação do estado do Tocantins que é alimentado constantemente pelos servidores das UC's, o Sistema Estadual de Gestão de Unidades de Conservação - GESTO. Este sistema foi desenvolvido pela Secretaria Estadual de Meio Ambiente e recursos hídricos (SEMARH) ${ }^{1} \mathrm{O}$ GESTO foi preparado para gerenciar as UC a partir da criação com foco na gestão da conservação da biodiversidade e também no gerenciamento administrativo e financeiro.

Por meio do sistema, o público pode encontrar todos os documentos das unidades de gestão do governo estadual como plano de manejo, Lei de criação das unidades, plano de uso público, entre outras informações acerca da unidade que se pretende pesquisar.

Em relação à atividade ecoturística que é realizada no PEJ, atualmente os únicos atrativos turísticos que são de gestão do parque são as Dunas e a Trilha da Serra do Espírito Santo. Existem outros atrativos do parque, que famílias que residem no interior deste fazem a gestão destes outros atrativos.

Em relação ao controle de acesso a estes atrativos, a entrevistada diz que apenas as dunas possuem um controle, o qual é realizado através do preenchimento de registro de visitantes que é feito pelo guarda-parque que fica de escala na base do atrativo, já o outro atrativo não há controle de visitação por falta de recursos humanos. Quanto aos demais atrativos, "justamente pela questão fundiária, o acesso ao parque é feito por qualquer pessoa pelas rodovias estaduais" (Dados da entrevista 02, 2016).

Em relação à pergunta se no PEJ existe algum sistema utilizado atualmente para o controle de entrada de turistas, e que repasse algum tipo de verba ou imposto, tanto para o parque quanto as prefeituras, a entrevistada nos relatou que não há este controle, e que "existe uma 
contribuição voluntária na entrada das Dunas. Onde o recurso arrecadado é utilizado na gestão do atrativo e na unidade como um todo" (Dados da entrevista 02, 2016).

As agências de viagens que fazem roteiros ao parque também não repassam nenhuma taxa ao parque, pois não existem taxas instituídas que sejam repassadas para a UC.

No que tange a capacidade de carga para os atrativos existe somente um estudo dos atrativos turísticos mais antigos, que já existe desde a criação da unidade, "mas não é utilizado de forma adequada seja por falta de controle dos proprietários de atrativos ou em decorrência da logística da região" (Dados da entrevista 02, 2016).

Com relação à articulação e planejamento do turismo no parque e a firmação de parcerias, o responsável pelo programa de uso público é quem faz as articulações de acordo com as necessidades e demandas da unidade, seguindo o Plano de Manejo do parque. Existem parceiras com a prefeitura Municipal de Mateiros, através da Secretaria Municipal de Meio Ambiente e turismo, com a Secretaria Estadual de Turismo, com o setor de uso público do Naturatins com sede em Palmas, instituições educacionais entre outras, porém não é especificado qual o tipo de parceria existente.

A principal dificuldade na gestão do turismo no PEJ, considerada pela entrevistada é a questão fundiária, pois o parque não faz gestão de todos os atrativos dentro da UC, além da falta de ordenamento do acesso ao interior da unidade, falta de material informativo, falta de registro de operadores de turismo que atuam na unidade e falta de recursos humanos para desenvolver as atividades de escala nas bases de monitoramento da UC.

No que se refere à legislação ou plano de manejo que regulamenta a atividade turística a unidade possui Plano de Manejo e Plano de Uso Público que trata dos assuntos relacionados ao turismo na UC.

A equipe gestora do PEJ procura envolver as comunidades em torno em uma gestão participativa tornando comuns as pretensões de todos os preocupados quanto às questões socioambientais, culturais e econômicas. A interação da área protegida com a população é feita através de um Conselho Consultivo que apoia a ligação entre eles.

Os gestores do PEJ buscam impactar constantemente a comunidade para as questões voltadas para a conservação da diversidade biológica e também para o uso sustentável no desenvolvimento regional, promovendo a educação ambiental através de capacitações, palestras e oficinas que estimulam o uso sustentável dos recursos naturais (THE NATURE CONSERVANCY, 2012). 


\section{Voucher digital e gestão integrada do ecoturismo no PEJ}

Percebeu-se, que o ecoturismo é um ramo do turismo que vem crescendo de forma significativa, despertando nas pessoas a vontade de aproximar-se da natureza e poder estar em contato com o que ela tem de mais belo a oferecer, o que gera uma responsabilidade tanto ambiental como social, envolvendo além da natureza as populações locais e a forma de viver.

A prática do ecoturismo gera renda e diminui o impacto na natureza, por meio dessa atividade educativa que possibilita a conservação do local visitado e sua biodiversidade, gerando benefícios para as populações locais.

No entanto, verificou-se, para que a receita gerada do ecoturismo se reverta em benefícios para o desenvolvimento econômico e a conservação é necessária à utilização de alguns fatores essenciais, como estabelecer taxas turísticas; proporcionar o desenvolvimento e técnicas de conservação por meio do ecoturismo com o que for arrecado com a cobrança de taxas; envolver as comunidades próximas às áreas que ocorre essas atividades para o desenvolvimento econômico das mesmas.

Dessa forma é possível solucionar as externalidades negativas do turismo adotando medidas que estabeleçam controle de visitação, proibição de comportamentos de alto impacto ambiental. Um exemplo disso é o arquipélago de Fernando de Noronha (PE) que controlam as visitações já que os autores da degradação não compensam a sociedade pelo dano ambiental (SANTOS; KADOTA, 2012).

O procedimento de criação e gestão das UCs passa por diversas etapas e aspectos legais que necessitam de uma conexão entre as informações e quem as alimentam, caso isso ocorra de maneira desorganizada e diversificada incidiam vários problemas nos processos de gestão que necessitam de informações confiáveis e acessíveis.

Um exemplo, como foi citado, é o do município de Bonito-MS, que utiliza o Voucher único digital como um documento/ingresso de caráter regulamentador das atividades de visitação turística. O Voucher funciona como controle de capacidade de carga, pois é nele que se registra o número de visitante que cada atrativo recebe diariamente, no qual fica registrado em um sistema integrado ao ministério público que aplicará penalidades ao atrativo que exceder o limite anteriormente estabelecido no plano de manejo.

Um sistema de informação gerencial com base na gestão de uma UC caracteriza-se pela sua atividade contínua que busca a melhoria na qualidade dos resultados, assim os gestores e comunidade serão beneficiados com ganhos geridos de uma gestão eficaz.

O envolvimento da gestão pública faz com que efetivamente se arrecade impostos com o turismo para que os recursos sejam revestidos em melhoria para a população e também para a área visitada.

Analisando a gestão do PEJ e a atividade turística desenvolvida neste, pode-se verificar que necessitam incluir os donos dos atrativos que estão dentro do parque e que não são de gestão do PEJ, para gerar 
benefícios com um sistema integrado, tanto para os proprietários como para as comunidades vizinhas.

O controle que é realizado através de preenchimento de registro de visitantes não limita a quantidade permitida também não garante que os recursos gerados sejam distribuídos de forma adequada. Dessa forma apenas uma contribuição voluntária é feita na entrada das Dunas, e os recursos arrecadados são utilizados na gestão do atrativo e na unidade como um todo.

As agências de viagens que fazem roteiros para o PEJ não repassam nenhuma taxa ao parque, pois não existem valores instituídos que seja repassado para a UC, e com isso deixam de gerar renda, podendo levar um grande número de turistas causando danos ao ecossistema local.

Como não existe uma capacidade de carga para os atrativos apenas ocorreu um estudo de capacidade de carga para os atrativos mais antigos e que não é utilizado de maneira adequada por falta de controle dos proprietários e também em virtude da logística da região e isso não assegura um funcionamento com qualidade e segurança que 0 Voucher digital oferece.

Como a questão fundiária é uma das principais dificuldades, os gestores deverão criar um Conselho de Turismo que seja participativo e que envolva todos os interessados e desenvolvam atividades colaborativas.

No PEJ o uso de um instrumento de controle como o Voucher digital pode melhorar a qualidade do atendimento aos turistas, minimizar os impactos causados pela a atividade turística a partir do controle de capacidade de carga dos atrativos, proporcionando um ganho econômico maior e melhor distribuída para a cadeia produtiva do turismo.

Para implantação do Voucher digital no PEJ será necessário à criação de um Conselho de turismo que através de normativas possa regulamentar a atividade turística, tendo como objetivo fomentar o turismo de maneira organizada e sustentável no PEJ, apoiando as ações voltadas à cadeia produtiva do turismo e a comunidade local.

Contudo é necessária a criação de cursos de aperfeiçoamento e de qualificação para proporcionar as pessoas um diferencial na prestação de serviços, pois, os turistas estão cada vez mais exigentes e buscam serviços satisfatórios. Instruí-los quanto à importância da atividade turística para o desenvolvimento e conservação do PEJ poderá contribuir para um desenvolvimento turístico sustentável. É de grande relevância inserir capacidade de carga para os atrativos turísticos com objetivo de planejar e adequar à capacidade de suporte ao uso de visitação, garantindo a conservação ambiental a partir de um plano de manejo na área. 


\section{Considerações finais}

Esta pesquisa se propôs, como objetivo geral, analisar quais implicações existentes na aplicação do Voucher digital como ferramenta de gestão integrada do ecoturismo no PEJ, ao analisar a atual gestão, identificou-se que ainda não é feito um controle de capacidade de carga dos atrativos e que apenas contribuições voluntárias são feitas na entrada de alguns atrativos, com isso não se arrecada tributos que poderiam ser revestidos em melhorias para a comunidade e para os demais.

A análise da possibilidade de aplicação de uma ferramenta de caráter regulamentador nos atrativos do $\mathrm{PEJ}$ pode contribuir para o desenvolvimento do turismo tomando como exemplo o Voucher digital de Bonito-MS será de grande valia para a conservação da biodiversidade, aperfeiçoamento do atendimento aos turistas e a melhor distribuição dos recursos gerados do turismo.

Presume-se que a continuidade do processo de análise sobre 0 determinado tema se faz necessário para dar à comunidade e a cadeia produtiva do turismo impulso para a implantação e desenvolvimento do Voucher digital no PEJ.

Deve-se continuar o trabalho de pesquisa para que haja o interesse do poder público, gestores do PEJ e demais representantes da cadeia produtiva do turismo quanto às questões socioambientais na UC. Pesquisas que analisem os impactos do ecoturismo no PEJ, trabalhos sobre planejamento e gestão no parque, estudos de mercado, pesquisas de oferta e demanda, entre outros.

Assim, esperamos que tal trabalho contribua para a melhoria da gestão da atividade ecoturística no PEJ e que promova uma articulação entre o órgão gestor do Parque, Naturatins, as comunidades que vivem no Parque em torno e os empreendedores locais para que os propósitos do turismo sejam alcançados.

\section{Referências bibliográficas}

BATISTA, E. O. Sistemas de informação: o uso consciente da tecnologia para o gerenciamento. 2 ${ }^{\underline{a}}$ ed. São Paulo: Saraiva 2012.

BONITO. Decreto n. 144, de 12 de dezembro de 2011. Dispõe sobre o regimento interno do COMTUR, e dá outras providências. Diário Oficial dos Municípios do Estado do Mato Grosso do Sul. Campo Grande, MS, n. 0483, 15 dez. 2011, p. 13-15. Disponível em: http://www.turismo.bonito.ms.gov.br/base/www/turismo.bonito.ms.gov.br/med ia/attachments/1/1/524c285307bd6e9e0a3aad16c7ed806efc9b6c93cfe94 re gimento comtur.pdf. Acesso em: 26 abr. 2016.

CÉBALLOS-LASCURÁIN, H. O ecoturismo como um fenômeno mundial. In: LINDBERG, K; HAWKINS, D.E. (org.). Ecoturismo: um guia para planejamento e gestão. 5a ed. São Paulo: Senac São Paulo, 2005. 
CHAGAS, R.P. Politicas territoriais no Estado do Tocantins: um estudo de case sobre o jalapão. 2007, p. 133. Dissertação (Mestrado em Geografia Humana). Faculdade de Filosofia, Letras e Ciências Humanas, Universidade de São Paulo, 2007.Disponível em: http://www.teses.usp.br/teses/disponiveis/8/8136/tde-27112009-133840/ptbr.php. Acesso em: 18 mai. 2016.

CIA, I.E.M. A evolução de um modelo de Gestão Sustentável para o Ecoturismo em Bonito. In: BEZERRA, D. M. F.(org.). Planejamento e Gestão em Turismo. São Paulo: Roca, 2003 p. 65-73.

DENCKER, Ada de Freitas M. Pesquisa em Turismo: planejamento, métodos e técnicas. São Paulo: Futura, 2007.

JESUS, J.S.; SELVA, V.S.F. Ecoturismo como contribuição à gestão de unidades de conservação. Revista Nordestina de Ecoturismo, Aracaju, SE, v.2, n.1 p. 43, 2009. Disponível em: http://sustenere.co/journals/index.php/nature/article/view/ESS1983-

8344.2009.001.0006/31. Acesso em: 25 abr. 2016.

LAUDON, K.C.; LAUDON, J.P. Sistemas de informação gerencial. São Paulo: Pearson education do Brasil, 11를 2014.

LEITE, A. Todos fazendo Bonito: Uma historia de desenvolvimento territorial. Campo Grande/MS, 2015.

LINDBERG, K. Questões econômicas relativas à gestão do ecoturismo. In: LINDBERG, K; HAWKINS, D.E. Ecoturismo: um guia para planejamento e gestão. 5aㅡ ed. São Paulo: Senac São Paulo, 2005 p. 143-193.

LOHMANN, G.; PANOSSO NETTO, A. Teoria do Turismo: Conceitos, Modelos e Sistemas. São Paulo: Ed. Aleph, 2008.

MAPA DE LOCALIZAÇÃo DO JALAPÃO, 2012. Disponível em: http://www.hondamaniaco.com.br/moto-aventural. Acesso em: 31 mai. 2016.

MARIANO, A.B. Melhor Prática vencedora: Políticas Públicas (Não Capital) - Voucher Único Digital. S/D. Disponível em: http://www.turismo.gov.br/sites/default/turismo/noticias/acontece/download a contece/Bonito -

Polxticas Pxblicas RELATOS MELHORES PRxTICAS.pdf. Acesso em: 13 mai. 2016.

MARINHO, A.A. et al. Degradação ambiental causada pelo desenvolvimento turístico na cachoeira do formiga - parque estadual do jalapão. $S / D$. Disponível em: http://gesto.to.gov.br/site media/upload/gestao/documentos/Marinho et al Degradacao ambiental causada pelo desenvolvimento turistico na cacho eira do formiga Jalapao.pdf. Acesso em: 21 mai. 2016.

MOESCH, M.M. A produção do saber turístico. 2. Ed. São Paulo: Contexto, 2002. 
NASCIMENTO, N.N.; CARVALHO, G.P.; BALSAN, R. Potencialidades e problemas ambientais associados ao turismo no fervedouro do Mumbuca, região do Jalapão,TO. Anais Uso Público em Unidades de Conservação, Niterói, RJ, n. 1, v. 1, p. 1-9. 2013. Disponível em: http://www.uff.br/var/www/htdocs/usopublico/images/Artigos/2013/Artigo OL 25.pdf. Acesso em: 21 mai. 2016.

OLIVEIRA, C.M.; SABINO, J. Elementos da permacultura como indutores da sustentabilidade em atrativos turísticos de Bodoquena, Bonito e Jardim, Mato Grosso do Sul. Observatório de inovação do turismo, Brasília, DF, n 3 , v. 3 , p. 1-25. 2013, disponível em http://bibliotecadigital.fgv.br/ojs/index.php/oit/article/view/7875. Acesso em: 25 abr. 2016.

OLIVEIRA, M.M. Como fazer pesquisa qualitativa. 2 ed. Petropólis, RJ: Vozes, 2008.

REZENDE, D.A.; ABREU, A.F. Tecnologia da informação aplicada a sistemas de informação empresariais. São Paulo: atlas, 2009.

RODRIGUES, A.B. Ecoturismo no Brasil: possibilidades e limites. (org.) São Paulo: Contexto, 2003 p. 29-44.

RUSCHMANN, D.V.M. Turismo e Planejamento Sustentável: a proteção do meio ambiente. $12^{\mathrm{a}}$ ed. Campinas SP: Papirus, 2005.

SALGADO, C.M.M. Uso da informação no desenvolvimento do território turístico de Bonito (MS). 2007. 109 p. Dissertação (Mestrado em Desenvolvimento Local) - Universidade Católica Dom Bosco, Campo Grande, 2007. Disponível em: http://site.ucdb.br/public/mddissertacoes/7942-uso-da-informacao-no-desenvolvimento-do-territorioturistico-de-bonito-ms.pdf. Acesso em: 13 mai. 2016.

SANTOS, E.S.; PEQUENO, E.A.; RIBEIRO, K.T.; FREITAS, L.L. Desenvolvimento sustentável e o ecoturismo em Unidades de Conservação: discussões sobre o Parque Estadual do Jalapão (TO). Revista Brasileira de Ecoturismo, São Paulo, v.8, n.5, nov - 2015/jan - 2016, pp.579-596

SANTOS, G.E.O; KADOTA, D.K. Economia do Turismo. São Paulo: Aleph, 2012.

SIQUEIRA, D.E. História Social do Turismo. Rio de Janeiro: Garamond; Brasília, DF: Ed. Vieira, 2005.

SOLDATELI, M. Análises Regionais e Globais do Turismo: Impactos Ambientais Negativos no Contexto do Turismo de Natureza. São Paulo: Ed. Roca, 2005.

THE NATURE CONSERVANCY (TNC) E GOVERNO DO ESTADO DO TOCANTINS. Sistema informatizado de gestão de unidades de conservação - GESTO: Experiências, oportunidades e desafios do Estado do Tocantins para a excelência na conservação de Áreas Protegidas. $1^{\underline{a}}$ ed. Palmas-TO: The Nature Conservancy, 2012. Disponível em: http://www.nature.org/media/brasil/gesto.pdf. Acesso em: 17 mai. 2016. 
VIEIRA, J.F.L. Voucher único um modelo de gestão da atividade turística em Bonito - MS, 2003, 137 p. Dissertação (Mestrado em Desenvolvimento Local) Universidade Católica Dom Bosco, Campo Grande, 2003. Disponível em: http://site.ucdb.br/public/md-dissertacoes/7911voucher-unico-um-modelo-de-gestao-da-atividade-turistica-em-bonitoms.pdf. Acesso em: 20 mai. 2016.

\section{Nota:}

${ }^{1}$ Disponível para consulta pública no site www.gesto.to.gov.br. A utilização do GESTO permite a transparência nos recursos destinados as UCs que são registrados no banco de dados do sistema disponível em tempo real para os interessados e publica com transparência e rapidez se os recursos estão sendo destinados em compatibilidade com os objetivos das UC

Dione Cley Bento de Abreu: Universidade Federal do Tocantins, Araguaína, TO, Brasil.

E-Mail: dionycley200@hotmail.com

Link para o currículo Lattes: http://lattes.cnpq.br/0526337928035528

\section{Letícia Lima de Freitas:}

E-Mail: leticialif@yahoo.com.br

Link para o currículo Lattes: http://lattes.cnpq.br/9895014743972619

Data de submissão: 27 de agosto de 2016

Data de recebimento de correções: 03 de outubro de 2016

Data do aceite: 11 de novembro de 2016

Avaliado anonimamente 